\title{
STRATEGI INKUBASI BISNISSUATU STARTUP DIGITAL MELALUI MODEL PENGEMBANGAN PASABARU DI SUMATERA BARAT
}

\author{
Donard Games $^{*}$ dan Dessy Kurnia Sari \\ Fakultas Ekonomi, Universitas Andalas \\ ${ }^{*}$ Email : donardgames@eb.unand.ac.id
}

\begin{abstract}
ABSTRAK
Pengembangan startup digital telah menjadi suatu hal yang penting untuk dilakukan berupa produkproduk seperti aplikasi, website dan online platform lainnya bisa membantu produk-produk yang dihasilkan oleh usaha mikro dan kecil dan startup untuk bisa dipasarkan dengan cara yang lebih ekonomis dan tepat sasaran. Hanya saja, tidak mudah untuk mengembangkan suatu online platform berbasis di Sumatera Barat yang memiliki karakteristik tertentu dalam ekosistem industri kreatif. Untuk itu dibutuhkan strategi inkubasi yang bukan hanya mendampingi dan melatih tim Pasabaru dari strategi konseptual dan pendampingan dilapangan. Selanjutnya pengembangan aplikasi Pasabaru mengalami beragam situasi menuntut respon dan perubahan segera. Disamping itu juga dituntut agar bisa bertransformasi menuju bisnis digital yang sesungguhnya.
\end{abstract}

Kata Kunci: online platform, strategi bisnis, inkubasi, startup digital

\section{Business Incubation Strategies for an Online Platform Through The Case of Pasabaru in West Sumatra}

\begin{abstract}
Transforming digital startups into high growth businesses have become a strategic issue nowadays. This is partly because online platforms have played a greater role in assisting small and medium enterprises to sell their products effectively. However, it is safe to say that it is not easy to develop online platforms in the context of West Sumatra, Indonesia. Pasabaru, an online platform that connects between farmers, small business owners and customers in West Sumatra, has some strategic developments that perhaps can indicate a way to transform digital startup in West Sumatra into a higher level of business organization. Here the role of incubation strategies is important to make certain that startup digital can find a way to enhance their business performance.
\end{abstract}

Keywords: online platform, inovation, business strategies, incubation, digital startup

\section{PENDAHULUAN}

Selama ini seringkali produk-produk hasil inovasi dosen maupun usaha mikro kecil dan menengah (UMKM) mengalami kendala dalam meraih konsumen. Tidak mudah untuk menjangkau konsumen yang tepat untuk produk-produk yang dihasilkan bahkan meski produk-produk tersebut memiliki kualitas yang baik. Salah satu solusi untuk masalah tersebut adalah penggunaan dan pengembangan online platform. Dalam konteks kekinian, penggunaan online platform untuk edukasi, promosi, dan ekspansi pasar sudah merupakan suatu kebiasaan dan kebutuhan. Dengan demikian, dibutuhkan suatu online platform yang bisa dimanfaatkan secara maksimal untuk berbagai kepentingan.

Idealnya, online platform yang dikembangkan berasal dari pemahaman dan kepentingan yang sama dengan dengan yang dibutuhkan oleh konsumen maupun 
produsen. Dalam hal ini, Pasabaru bisa menjadi online platform yang diharapkan bisa menjadi bagian dari hilirisasi dan pemasaran produk-produk dari para dosen maupun pemilik UMKM. Pasabaru adalah aplikasi berbasis android buatan putra daerah dan memahami pasar lokal Sumatera Barat. Pertanyaan yang menjadi poin penting adalah bagaimana agar Pasabaru mampu menjadi agen hilirisasi hasil riset atau pemasaran produk UMKM yang berperan penting dalam pengembangan inovasi produk-produk berbasis di Sumatera Barat.

Peran e-commerce sebagai penggerak perekonomian sekaligus peluang bisnis terutama bagi UMKM sulit untuk dibantah dalam konteks Indonesia saat ini (Triandini et.al., 2013). Dibutuhkan strategi khusus untuk menjadikan online platform bukan hanya didominasi oleh pemain besar atau mereka yang berada di kota-kota besar. Mereka yang berada di daerah seperti Sumatera Barat juga harus proaktif mengambil peran. Dalam hal ini, pemanfaatan aplikasi Pasabaru bisa menjadi salah satu bentuk terobosan. Aplikasi ini bisa menjadi alat penghubung antara petani plus usaha kecil dan konsumen. Hal yang menjadi kekuatan utama dari Pasabaru adalah ini adalah Pasabaru memiliki fondasi riset dan inkubasi dari inkubator Universitas Andalas yang merupakan inisiatif dari alumni Universitas Andalas.

Pasabaru adalah sebuah aplikasi yang mewadahi para petani dan pelaku usaha keciluntuk dihimpun bersama dan dipasarkan dalam sebuah aplikasi yang berkonsep GPS radius terdekat. Dengan demikian, pembelian dapat dilakukan dengan cepat, aman, dan praktis. Aplikasi Pasabaru sudah tersedia diberbagai macam alat komunikasi dan media seperti website, dan android, sedangkan untuk i-Phone masih dalam tahap pengerjaan. Target market Pasabaru adalah kelas menengah yang melek teknologi, akrab dengan online platform sekaligus penyuka kemudahan dalam bertransaksi online.

Selanjutnya, Pasabaru memiliki memiliki model bisnis yang berpotensi untuk berkembang lebih jauh. Hal ini bisa terwujud dalam kenyataan jika Pasabaru mampu menghimpun segenap kekuataannya sebagai online platform. Dalam hal ini, perumusan Business Model Canvas bisa membantu Pasabaru untuk mengidentifikasi kekuatannya yang bisa menarik perhatian pasar.

Basis dari keberadaan Pasabaru didukung oleh sejumlah riset yang mengonfirmasi semakin pentingnya kekuatan bisnis online dan e-commerce dalam konteks usaha mikro dan kecil di Indonesia. Games (2018), mengidentifikasi bahwa usaha mikro dan kecil di Sumatera Barat justru harus melihat online platform sebagai peluang bisnis yang seharusnya dimanfaatkan untuk bisa meningkatkan skala usahanya. Di sisi lain, risetnya juga mendapatkan bahwa konsumen di daerah ini juga sudah melihat pembelian online sebagai sesuatu yang tidak asing lagi. Selanjutnya, Sari (2015) menemukan bahwa konsumen di Sumatera Barat sudah mulai memiliki standar tertentu dalam hal kualitas dan aspek kesehatan produk. Dengan demikian, ini bisa menjadi peluang bagi usaha mikro dan kecil untuk bisa menyediakan produk dengan standar tersebut.

Tujuan kegiatan untuk pengembangan startup digital diharapkan bisa memberikan perspektif baru dan pencapaian sebagai berikut: 1. Pasabaru bisa memiliki strategi pengembangan yang mampu merespon perubahan lingkungan, 2. Pasabaru bisa mendapatkan pelatihan tentang model bisnis dan bisa mengedukasi pasar dan partner yang sesuai dengan model bisnis tersebut dan 3. Pasabaru bisa mendapatkan partner (petani dan UMKM) dan user (konsumen) yang sesuai dengan model bisnis Pasabaru. 


\section{METODE}

Metode yang digunakan dalam kegiatan ini bertujuan untuk membantu peningkatan performa startup digital Pasabaru adalah sebagai berikut:

A. Konsultasi

Konsultasi dilaksanakan oleh tim Pasabaru dengan CEO Andri Syahputra dan timnya dengan tim pelaksana program hilirisasi riset (Donard Games dan Dessy Kurnia Sari) terutama pada dua minggu pertama Bulan Agustus 2018.

Fokus utama dalam sesi konsultasi adalah strategi pengembangan inovasi Pasabaru. Dalam hal ini, model bisnis yang dikembangkan berbasis pada perumusan business model canvas. Secara umum, manajemen strategi bisnis dan gambaran situasi saat ini dan di masa yang akan datang bisa digambarkan dalam satu halaman strategi bisnis (Osterwalder et al., 2010). Dengan merumuskan business model canvas ini, maka Pasabaru bisa bergerak lebih leluasa sekaligus lebih fokus pada customer segments yang untuk saat ini dituju.

\section{B. Pendampingan}

Inti sari dari inkubasi adalah pendampingan dalam tiga tahapan, yaitu pra-inkubasi, inkubasi, dan pasca inkubasi. Dalam kasus Pasabaru, program yang tim pelaksana lakukan adalah kombinasi dari tiga tahapan di atas dalam waktu tiga bulan (September sampai dengan Oktober 2018). Dengan demikian, terjadi akselerasi dalam inkubasi Pasabaru. Fokus inkubasi Pasabaru adalah pada aspek marketing daripada aspek teknis. Ini bukan hanya karena tim pelaksana memiliki kompetensi di bidang marketing dan inovasi, tetapi juga karena pada dasarnya.

\section{Penyuluhan}

Metode ini dilaksanakan dengan melakukan edukasi pada pemangku kepentingan utama (main stakeholders), yaitu konsumen dan mitra (partner). Yang disebut terakhir ini akan menjadi fokus utama Pasabau karena mereka yang akan menjadi pemasok utama Pasabaru. Penyuluhan dilakukan in situ yaitu langsung di tempat produksi mitra dengan menjelaskan hal-hal utama berupa model bisnis Pasabaru, aspek teknis penggunaan aplikasi Pasabaru, sistem bagi hasil keuntungandan atau selisih harga. Kegiatan ini dilaksanakan pada Bulan Oktober dan November 2018.

\section{HASIL DAN PEMBAHASAN}

Sebagaimana disampaikan pada bagian sebelumnya, maka hal pertama dan utama yang dilakukan oleh tim Pasabaru dan tim pelaksana program dari Fakultas Ekonomi Unand adalah perumusan Business Model Canvas. Selanjutnya, tim ini juga berkolaborasi dalam tahapaninkubasi berupa pendampingan dan pelatihan. Berikut ini rincian penjelasan hal-hal tersebut:

\section{A. Perumusan Business Model Canvas}

Pembuatan business model canvas bukan sekadar masalah pembuatan satu halaman yang menjadi dokumen formalitas saja. Lebih daripada itu, model bisnis ini bisa 
menjadi bagian dari transformasi bisnis Pasabaru sekaligus representasi kemampuan Pasabaru untuk merespon perubahan cepat yang terjadi di sekeliling mereka.

Pada awal berdirinya di tahun 2016, Pasabaru di desain untuk menjadi aplikasi yang menghubungkan penyedia jasa seperti pemotong rumput dan tukang ledeng dan konsumen. Ini belum bisa diwujudkan karena terbukti sangat susah untuk melakukan standardisasi jasa di Kota Padang. Selanjutnya, Pasabaru mengubah strategi bisnisnya untuk menjadi penghubung antara konsumen dan penyedia kebutuhan harian seperti air galon dan gas LPG. Ini didasari pula pada kenyataan bahwa model bisnis seperti ini lebih menjanjikan uang kas yang lebih cepat daripada model yang sebelumnya.

Perubahan ini menjadi penting karena Pasabaru memiliki sumber daya yang terbatas terutama dari segi modal kerja. Perubahan model atau strategi bisnis tanpa melupakan identitas stratup digital yang sedari awal sudah dirumuskan ini dikenal sebagai pivot dan ini bisa menjadi kekuatan penting bagi suatu startup digital. Meskipun demikian, tidak ada jaminan juga bahwa pivot ini bisa berhasil. Ketika Go-Jek ekspansi ke Kota Padang dan cepat atau lambat mereka akan merambah bisnis yang akan dimasuki Pasabaru, bisa dipastikan Pasabaru yang kalah segalanya akan babak belur. Lagi, Pasabaru harus mampu fleksibel untuk bisa menggeliat dengan strategi bisnis baru dalam rangka merespon perubahan cepat yang terjadi di sekelilingnya.

Aplikasi Pasabaru dalam waktu dekat akan meluncurkan aplikasi berbasis android yang sudah bisa melayani konsumen dan mitra Pasabaru. Strategi bisnisnya sederhana dan juga telah berubah pula, yaitu menjadi aplikasi penghubung petani, pemilik usaha kecil (UMKM) yang mengolah hasil pertanian dan konsumen. Sebagaimana bisa dilihat pada Gambar 1 di bawah ini, perubahan itu terwakili dari perubahan customer segments. 


\begin{tabular}{|c|c|c|c|c|}
\hline \multirow[t]{2}{*}{$\begin{array}{l}\text { Mitra Kunci } \\
\text { - Kelompok tani } \\
\text { - Dosen dengan } \\
\text { fokus hilirisasi } \\
\text { riset pertanian } \\
\text { - Koperasi dan } \\
\text { kelompok tani } \\
\text { - Toko tani } \\
\text { - Dinas pertanian }\end{array}$} & $\begin{array}{ll}\text { Kegiatan Utama } \\
\text { - } & \text { Mencari mitra } \\
& \text { Pasabaru) } \\
\text { - } & \text { Membina mitra } \\
\text { - } & \text { Menstandardisasi } \\
& \text { harga dan skill } \\
\text { mitra } & \\
\text { - } & \text { Perbaikan } \\
\text { - aplikasi android } \\
\text { - Marketing } \\
\text { campaign }\end{array}$ & \multirow[t]{2}{*}{\begin{tabular}{|l} 
Value Proposition \\
- Online platform \\
yang didesain \\
mudah, praktis, \\
cepat, aman bagi \\
konsumen kelas \\
menengah di \\
Sumatera Barat \\
yang \\
membutuhkan \\
produk pertanian \\
yang berkuaitas \\
- Ikut \\
menyejahterakan \\
pelaku usaha \\
yang selama ini \\
tidak berada \\
dalam arus utama \\
perekonomian
\end{tabular}} & $\begin{array}{l}\text { Hubungan } \\
\text { Pelanggan } \\
\text { - Diskon } \\
\text { - free ongkos kirim } \\
\text { secara periodik } \\
\text { - Memilih mitra } \\
\text { terbaik setiap } \\
\text { bulan } \\
\text { - Mengadakan } \\
\text { seminar dan } \\
\text { pelatihan bagi } \\
\text { partner dan user } \\
\text { serta masyarakat } \\
\text { umum Featuring } \\
\text { pelanggan setia } \\
\text { pada medsos } \\
\text { Pasabaru }\end{array}$ & \multirow[t]{2}{*}{$\begin{array}{l}\text { Segmen Pasar } \\
\text { A.Petani/ Toko / } \\
\text { Penjual / hasil } \\
\text { riset dosen } \\
\text { Penyedia } \\
\text { produk } \\
\text { pertanian sayur } \\
\text { dan buah dan } \\
\text { hilirisasi } \\
\text { produk } \\
\text { pertanian sayur } \\
\text { dan } \\
\text { buah(Partner) } \\
\text { B.Pembeli } \\
\text { (Pasabaru } \\
\text { User)-kelas } \\
\text { menengah di } \\
\text { Sumatera Barat } \\
\text { yang } \\
\text { menghargai } \\
\text { kemudahan } \\
\text { dan kualitas } \\
\text { produk serta } \\
\text { gaya hidup } \\
\text { sehat }\end{array}$} \\
\hline & 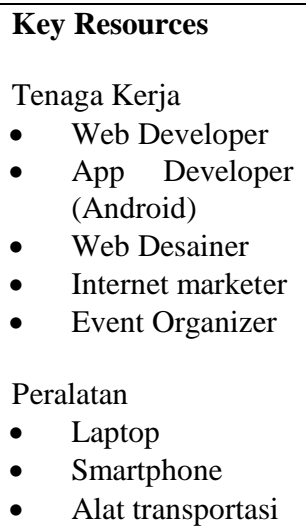 & & \begin{tabular}{ll}
\multicolumn{2}{l}{ Channels } \\
1. & Teman \\
2. & Word of Mouth \\
3. & Social Media \\
4. & Pds \\
5. & Radio Release \\
6. & Iklan Unik
\end{tabular} & \\
\hline \multicolumn{2}{|l|}{$\begin{array}{ll}\text { Struktur Biaya } \\
\text { - } \quad \text { Develop App } \\
\text { - } \quad \text { Operasional harian } \\
\text { - } \quad \text { Transportasi }\end{array}$} & \multicolumn{3}{|c|}{\begin{tabular}{|l|l} 
Revenue Streams \\
- $\quad$ Selisih harga produsen dan harga jual konsumen \\
- Iklan
\end{tabular}} \\
\hline
\end{tabular}

Gambar 1. Business Model Canvas Pasabaru 15 September 2019

Pada rumusan model bisnis terbaru, partner utama dari Pasabaru adalah petani dan UMKM produsen hasil tani dan hilirisasi produk pertanian termasuk hilirisasi yang dilakukan oleh dosen atau periset di perguruan tinggi danatau lembaga riset lainnya. Untuk tahap awal pelaksanaan strategi ini, Pasabaru berfokus pada sayur, buah, dan produk pertanian organic. Setelah beberapa bulan, Pasabaru akan mengeksplorasi hilirisasi produk pertanian. 
B. Pendampingan dan Pelatihan

Pendampingan dilakukan selama tiga bulan (Agustus sampai dengan Oktober 201) dengan menggabungkan tahapan pra-inkubasi, inkubasi, dan pasca inkubasi. Berikut ini sejumlah hal yang dilakukan selama tiga bulan tahapan inkubasi:

\section{Perincian Strategic Model Business}

Perumusan strategic business model sudah dilaksanakan pada bagian sebelumnya dan sudah berhasil diidentifikasi bulan September 2018. Selanjutnya, dilakukan perincian dari strategi tersebut dalam Bulan September, Oktober, dan November 2018.

Beberapa isu pokok yang di identifikasikan bersama dalam hal ini, yaitu: siapa target market mitra Pasabaru yang pantas untuk dieksplorasi lebih lanjut; berapa lama menggarap target market saat in dan apakah kemudian akan beralih ke lini produk yang berbeda; berapa jumlah mitra yang bisa didekati dan dilakukan kerjasama dalam proses saat ini; dan bagaimana mendapatkan cash flow dari model bisnis yang dipilih untuk saat sini.

\section{Pelaksanaan Marketing Campaign}

Aspek teknis Pasabaru sudah bisa dikelola oleh tim teknis Pasabaru yang siap untuk memperbaiki desain maupun system aplikasi. Hal yang lebih rumit untuk dilakukan adalah penetrasi pasar dengan tujuan utama mengampanyekan Pasabaru sebagai online platform untuk petani dan konsumen. Ada dilema dalam hal ini, yaitu dalam hal pricingstrategy. Strategi ini terkait dengan pemilihan produk dan terutama pemilihan target market. Jika Pasabaru berfokus pada kelas menengah atas, maka Pasabaru bisa menyediakan produk-produk premium dengan kualitas yang sangat baik namun dengan harga yang premium pula.

Di sisi lain, Pasabaru bisa bersaing dengan kompetitor ternasuk mereka yang sensitif terhadap harga karena Pasabaru bisa memberikan harga yang kompetitif. Ini disebabkan oleh model bisnis Pasabaru yang memotong mata rantai distribusi produk pertanian sayur dan buah.

Menyikapi hal ini, tim pelaksana dan tim Pasabaru memutuskan untuk memilih mereka, kelas menengah, yang memiliki daya beli untuk produk premium karena mereka mementingkan nilai-nilai seperti gaya hidup sehat. Lebih lanjut, marketing campaign yang dilaksanakan harus selaras dengan itu. Tim Pasabaru telah mendesain leaflet, standingbanner, konten media sosial yang selaras dengan kepentingan dan profil target market.

3. Pendekatan terhadap Partner Utama dan User

Tim Pasabaru dibekali dengan kemampuan untuk melakukan presentasi dan komunikasi efektif dengan calon mitra. Termasuk dalam hal ini adalah edukasi terhadap keberadaan dan manfaat aplikasi Pasabaru pada partner dan konsumen yang potensial bergabung dengan Pasabaru.

Tidak mudah mengumpulkan dan mengedukasi petani, pemilik UMKM, dan konsumen untuk masuk ke dalam sistem Pasabaru. Hal yang bisa dilakukan secara cukup maksimal adalah menetapkan target mitra dan konsumen secara tepat dan jelas dan mulai dari situ untuk mengembangkan potensi pasar Pasabaru. Tim Pasabaru mendatangi calon mitra secara langsung sehingga memudahkan calon mitra. 
Komunikasi dilaksanakan dengan bergaya informal yang justru memberikan saling kesepahaman antara Pasabaru dan calon mitranya. Untuk user atau konsumen, dilakukan pertemuan dengan mahasiswa S1 dan S2 serta pengguna seperti ibu-ibu dari kalangan kelas menengah maupun rumah tangga yang meminati Pasabaru. Respon yang didapat cukup baik terbukti dari sudah adanya tambahan mitra mencapai 30 produk yang sudah sesuai dengan profil Pasabaru. Untuk user, respon lebih banyak terkait tampilan aplikasi yang dianggap belum prima dan ini sudah diperbaiki oleh Tim Pasabaru.

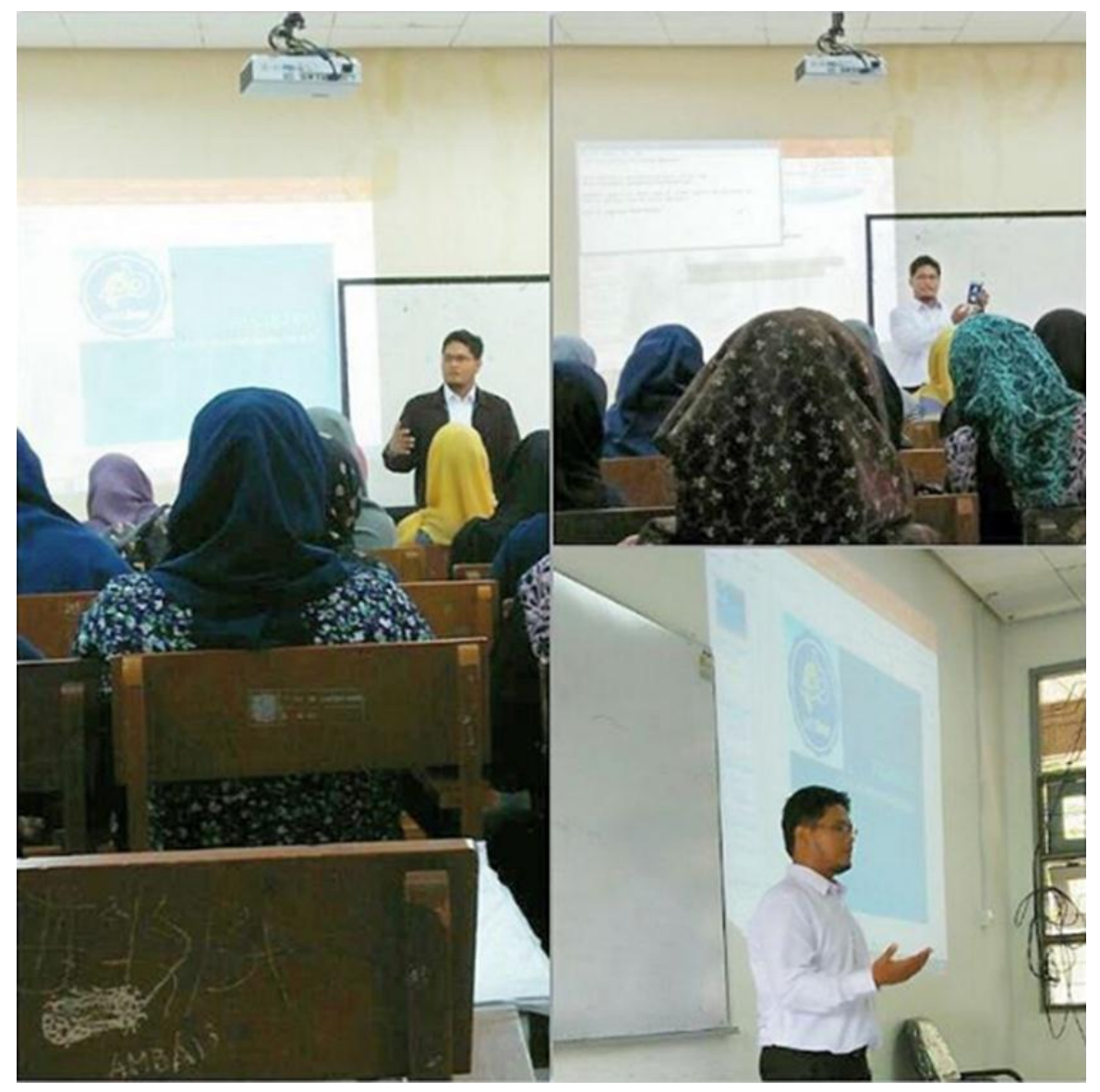

Gambar 2. Edukasi Partner dan User

Pendekatan inkubasi yang dilakukan dalam mendampingi Pasabaru pada dasarnya mengikuti filosofi dan saran dari Ries (2011) yang mempopulerkan istilah "Lean Startup" yang menekankan pada pemaksimalan sumber daya yang dimiliki startup. Di sini biasa dilaksanakan percobaan untuk bisa mengetahui respon pasar segera sehingga startup bisa secara cepat mengadopsi perubahan. Dalam hal ini, dikenal istilah Minimum Viable Product (MVP) yang menegaskan bahwa tidak perlu selalu memiliki tipe ideal suatu produk untuk bisa mendekati pasar. Proses pembelajaran yang cepat dan fleksibel menjadi kunci di sini. Strategi inkubasi Pasabaru mengikuti prinsip-prinsip demikian. Sebagai tambahan, dalam kasus Pasabaru yang berada pada konteks iklim inovasi yang tidak terlalu mendukung, diperlukan ketahanan (Resilience) dari startup digital. 
Ketahanan ini membutuhkan pendalaman dan pengamalan pengetahuan melalui strategic managerial thinking (Gunasekaran et al., 2011) dan keseimbangan antara pandangan jangka pendek dan panjang (Ates dan Bititci, 2011).

Ada satu isu penting lagi yang selalu menjadi bagian dari permasalahan Pasabaru, yaitu pendanaan. Kesulitan modal kerja dan uang kas masuk bisa diatasi sebenarnya dengan adanya seed capital bagi usaha rintisan digital seperti Pasabaru. Games (2017), menekankan pada bantuan modal kerja yang bisa memberikan nafas bagi startup digital yang potensial. Tentu saja pemaksimalan sumber daya yang ada adalah pilihan logis. Tambahan pula, Pasabaru didampingi oleh inkubator bisnis teknologi (InBisTek) Universitas Andalas dengan seed capital oleh Universitas Andalas. Ini bisa menjadi paket insentif yang bisa membantu pelaksanaan prinsip lean startup yang disampaikan sebelumnya.

\section{KESIMPULAN DAN SARAN}

Program akselerasi inovasi startup digital Pasabaru bisa menjadi salah satu bentuk role model pengembangan startup digital di Sumatera Barat yang memiliki keterbatasan dan iklim inovasi yang belum kuat. Inkubasi menjadi kunci dalam pengembangan startup digital Pasabaru. Dalam waktu tiga bulan dilakukan akselerasi dalam hal strategi inovasi dengan fokus utama penajaman target market terutama untuk mitra dan calon mitra Pasabaru. Tim Pasabaru berkolaborasi dengan tim peneliti Universitas Andalas sedari awal sampai dengan pendekatan ke partner dan user serta strategi mendekati pasar. Strategi utama yang dikembangkan adalah fokus pada target market kelas menengah yang mengapresiasi gaya hidup sehat dengan konsumsi makanan buah dan sayur serta jenis yang spesifik seperti produk-produk premium dan organik. Dalam bulan Desember 2018, Pasabaru berencana untuk beroperasi secara penuh dan mulai mendapatkan cashflow.

Strategi inkubasi yang berfondasi pada rumusan model bisnis yang tepat dan keterlibatan tim secara langsung pada proses penetrasi pasar dan pendekatan dengan calon mitra terbukti mempercepat kinerja Pasabaru yang pada masa sebelumnya cenderung stagnan. Adanya modal kerja dan insentif pendanaan menjadi hal penting di sini. Namun demikian, pendekatan strategi dan keterlibatan langsung tim Universitas Andalas yang berpengalaman dalam hal marketing dan inovasi bisa memberikan tingkat kepercayaan diri maupun penguatan bagi organisasi Pasabaru.

Secara umum, hal ini memberikan pembelajaran bagi strategi inkubasi startup digital di Sumatera Barat. Banyak hal yang harus dibenahi dalam perjalanan suatu startup digital, dan strategi inkubasi dengan prinsip lean startup yang memaksimalkan sumber daya ternbatas startup bisa menjadi salah satu upaya memberikan jalan bagi pengembangan lanjutan startup digital sehingga bisa bertransformasi menjadi bisnis yang berbasis pertumbuhan di Sumatera Barat.

\section{UCAPAN TERIMAKASIH}

Ucapan terima kasih disampiakan kepada Universitas Andalas, LPPM Uniersitas Andalas yang telah memberikan pendanaan melalui skema IBIIDU. Ucapan terima 
kasih juga disampaikan kepada tim Inkubator Bisnis Teknologi Universitas Andalas yang telah membantu dalam proses inkubasi.

\section{DAFTAR PUSTAKA}

Ates, A and U. Bititci. 2011. Change process: a key enabler for building resilient SMEs. International Journal of Production Research 49 (18): 5601-5618.

Games, D. 2018. Manifesto Kewirausahaan Indonesia. Gre Publishing, Yogyakarta.

Games, D. 2000. Generasi Baru Kewirausahaan Indonesia. Erka Publishing, Padang.

Gunasekaran, A. Rai, BK. Dan Griffin, M 2011. Resilience and competitiveness of small and medium size enterprises: an empirical research. International Journal of Production Research. 49(18): 5489-5509.

Osterwalder, A., Y Pigneur, A. Smith and 470 practioners from 45 countries. 2010. Business Model Generation. Self published

Ries, E. 2011. The Lean Startup: How Today's Entrepreneurs Use Continuous Innovation to Create Radically Succesful Business. Crown Business

Sari, D. K. 2015. Investigating the reasons muslims boycott foreign brand. Disertasi Doctoral. The University of Western Australia, Australia,

Triandini, E., Djunaidy, A. dan Siahaan, D. 2015. E-commerce adoption by SMEs in Indonesia: A literature review. Proceeding of International Conference Electronic, Information and Communication, ICEC 2013. 30 Januari-2 Februari. Bali, Indonesia. 